\title{
Receptor for advanced glycation end products (RAGE) regulates sepsis but not the adaptive immune response
}

Birgit Liliensiek, ${ }^{1,2}$ Markus A. Weigand, ${ }^{3}$ Angelika Bierhaus, ${ }^{2}$ Werner Nicklas, ${ }^{4}$ Michael Kasper, ${ }^{5}$ Stefan Hofer, ${ }^{3}$ Jens Plachky, ${ }^{3}$ Herman-Josef Gröne, ${ }^{6}$ Florian C. Kurschus, ${ }^{1}$ Ann Marie Schmidt, ${ }^{7}$ Shi Du Yan, ${ }^{7}$ Eike Martin, ${ }^{3}$ Erwin Schleicher, ${ }^{8}$ David M. Stern, ${ }^{9}$ Günter J. Hämmerling, ${ }^{1}$ Peter P. Nawroth, ${ }^{2}$ and Bernd Arnold ${ }^{1}$

\begin{abstract}
${ }^{1}$ Department of Molecular Immunology, Division of Tumor Immunology, German Cancer Research Center, Heidelberg, Germany. 2Department of Internal Medicine I and ${ }^{3}$ Department of Anesthesiology, University of Heidelberg, Heidelberg, Germany. ${ }^{4}$ Department of Central Animal Laboratories, German Cancer Research Center, Heidelberg, Heidelberg, Germany. ${ }^{5}$ Department of Anatomy, Technical University Dresden, Dresden, Germany. ${ }^{6}$ Department of Cellular and Molecular Pathology, German Cancer Research Center, Heidelberg, Heidelberg, Germany. ${ }^{7}$ Departments of Pathology and Surgery, Columbia University, New York, New York, USA. ${ }^{8}$ Department of Medicine IV, Tübingen, Germany. ${ }^{9}$ Medical College of Georgia, Augusta, Georgia, USA
\end{abstract}

\begin{abstract}
While the initiation of the adaptive and innate immune response is well understood, less is known about cellular mechanisms propagating inflammation. The receptor for advanced glycation end products (RAGE), a transmembrane receptor of the immunoglobulin superfamily, leads to perpetuated cell activation. Using novel animal models with defective or tissue-specific RAGE expression, we show that in these animal models RAGE does not play a role in the adaptive immune response. However, deletion of RAGE provides protection from the lethal effects of septic shock caused by cecal ligation and puncture. Such protection is reversed by reconstitution of RAGE in endothelial and hematopoietic cells. These results indicate that the innate immune response is controlled by pattern-recognition receptors not only at the initiating steps but also at the phase of perpetuation.
\end{abstract}

\section{Introduction}

The adaptive and the innate immune systems are both capable of initiating inflammation. The two are interconnected at several levels, including the synthesis and action of cytokines, molecules regulating cell-cell interactions, and the activation of transcription factors (1-9). While the molecular events leading to activation of the immune response are well understood, less is known about factors that perpetuate inflammation. One mechanism considered central in the cross-talk between the innate and adaptive immune systems is the redox-dependent activation of the transcription

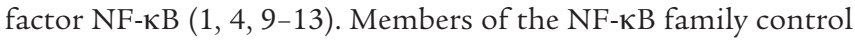
the initiation of inflammation by regulating expression of leukocyte adhesion molecules, cytokines, and other factors (10-13), but are also central in terminating inflammation (14-18). This leaves unanswered the question of the perpetuation of inflammation of the adaptive and innate immune responses.

Recently, studies of the receptor for advanced glycation end products (RAGE) (19-23), a member of the immunoglobulin superfamily (23) whose gene is located in the vicinity of the MHC

Nonstandard abbreviations used: antithrombin III (AT III); (carboxymethyl)lysine (CML); cecal ligation and puncture (CLP); Cre recombinase (Cre); delayed-type hypersensitivity (DTH); electrophoretic mobility-shift assay (EMSA); experimental autoimmune encephalomyelitis (EAE); graft-versus-host disease (GvHD); high-mobility group protein B1 (HMGB1); hypoxanthine guanine phosphoribosyl transferase (HPRT); methylated BSA (mBSA); myelin basic protein (MBP); myelin oligodendrocyte glycoprotein (MOG); partial pressure of arterial oxygen $\left(\mathrm{PaO}_{2}\right)$; pattern-recognition receptor (PRR); receptor for advanced glycation end products (RAGE); soluble RAGE (sRAGE); specific pathogen-free (SPF).

Conflict of interest: The authors have declared that no conflict of interest exists.

Citation for this article: J. Clin. Invest. 113:1641-1650 (2004).

doi:10.1172/JCI200418704 complex in humans and mice $(23,24)$, have served to partially answer this question. Previous studies suggested that binding of ligands to RAGE results in rapid and sustained cellular activation and gene transcription (25). Its involvement in inflammation has been suggested by many findings. First, RAGE is upregulated in all inflammatory lesions studied, including rheumatoid arthritis (26-28), inflammatory kidney disease (29-32), arteriosclerosis (33-36), inflammatory bowel disease (37), and others (38-42). Second, soluble RAGE (sRAGE), which is a truncated form of the receptor spanning the extracellular ligand-binding domain (and which therefore competes with cellular RAGE for ligand binding), reduced inflammatory responses in all models tested so far (35-40, 42, 43), such as delayed-type hypersensitivity (DTH), colitis, and periodontitis. Studies using $\mathrm{F}(\mathrm{ab})_{2}$ fragments to block ligand binding to RAGE confirmed these results, especially at the highest dose tested.

As reported for pattern-recognition receptors (PRRs) of the innate immune system, RAGE is a receptor that recognizes a threedimensional structure rather than a specific amino acid sequence $(5,6,8,44)$. RAGE binds several peptides, including advanced glycated end products, amyloid $\beta$-peptide, $S 100$ proteins, and amphoterin, also known as high-mobility group protein B1 (HMGB1), all of which are characterized by the presence of $\beta$-sheet structures and fibrils $(20,28,45)$. sRAGE functions as a "decoy" by binding RAGE ligands and preventing their interaction with cell surface RAGE. However, sRAGE also has the capacity to prevent ligands from interacting with receptors other than RAGE. In order to be certain that a particular response was RAGE dependent, it was necessary to generate and study homozygous RAGE-null $\left(R A G E^{-/-}\right)$ mice. We have generated such mice devoid of RAGE, as well as mice 

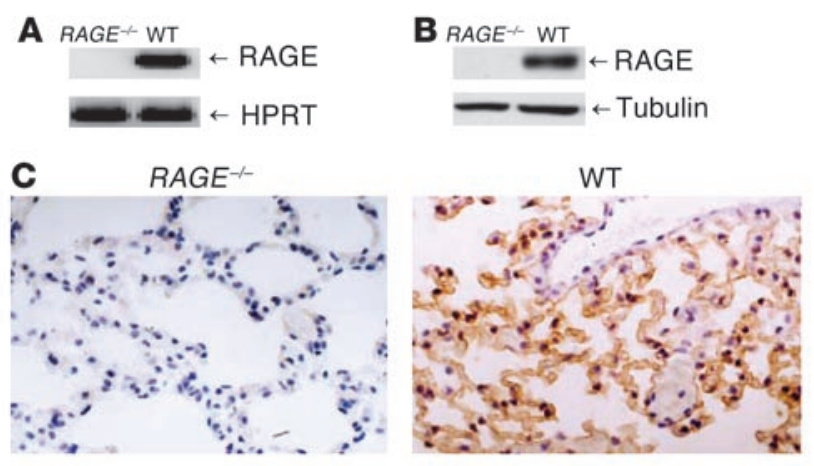

Figure 1

Generation and characterization of $R A G E^{-/-}$mouse line. (A) RT-PCR of lung tissue from $R A G E^{-/-}$and WT mice analyzed for RAGE mRNA expression. WT indicates $R A G E^{+++}$littermates. HPRT was used to demonstrate equal loading. (B) Western blot analysis of $R A G E^{-1}$ and WT lung tissue analyzed for the presence of RAGE protein $(43 \mathrm{kDa})$. Tubulin demonstrates equal loading. (C) Immunohistology for RAGE protein in WT and $R A G E^{-1-}$ lung tissue. Brown staining indicates RAGE expression; magnification, $\times 400$.

with tissue-specific expression, in order to study the role of this $P R R$ in adaptive and innate immune responses.

The data presented here show that $R A G E^{-1-}$ mice reacted normally in different models of the adaptive immune response tested but were protected in a model of lethal septic shock, the latter dependent on the innate immune response. These data indicate that the innate immune response is controlled by PRRs not only at the point of initiation but also during the propagation phase.

\section{Results}

Generation of mice carrying a $R A G E^{-1-}$ mutation or overexpressing $R A G E$ in specific tissues. For the generation of a $R A G E^{-/-}$mouse line, essen- tial elements encoding the extracellular domain of RAGE (exons 2-7) were flanked by two loxP sites in the same orientation so that after exposure to Cre recombinase (Cre), the intervening genomic sequences were deleted. Mice heterozygous for Cre recombination were bred to homozygosity to generate the $R A G E^{-1-}$ mouse line. The abrogation of RAGE expression at the mRNA level was analyzed by RT-PCR of lung tissue, in which RAGE is constitutively expressed at high levels. No RAGE mRNA could be detected in $R A G E^{-/-}$mice with primers for the extracellular RAGE domain (Figure 1A). To confirm the abrogation of RAGE expression, we used different primers covering the entire RAGE molecule and detected no transcripts (data not shown). In addition, in tissues with low RAGE expression in wild-type (WT) mice (heart, liver, kidney, and brain), no RAGE message could be detected in $R A G E^{-/-}$mice (data not shown). The absence of RAGE protein was demonstrated by Western blot and immunohistochemistry of lung tissue (Figure 1, B and C).

Hematopoietic and endothelial cells are cell types important in inflammatory reactions during an immune response. Therefore, mice overexpressing RAGE in hematopoietic and endothelial cells were generated. Two distinct regulatory elements of the murine Tie2 gene were chosen to drive the RAGE transgene: a $2.1-\mathrm{kb}$ promoter sequence and a 10.5 -kb fragment including enhancer fragments (Figure 2A) (46). The presence of the RAGE transgene was analyzed by Southern blot of DNA obtained from tail tissue (Figure 2B). RAGE expression was evaluated in different vascularized tissues of heterozygous Tie2RAGE mice (mice with the Tie2 promoter and Tie2 enhancer to drive RAGE expression) by RT-PCR (Figure 2C). Strong upregulation of RAGE transcripts was detected in kidney, brain, and liver, organs with rather low RAGE expression in healthy WT mice, while no upregulation of RAGE mRNA could be detected in the lung (Figure 2C). This was most likely due to the high constitutive RAGE expression evident in lung epithelia of WT mice (47) not affected by Tie2-driven overexpression of RAGE. RT-PCR was also performed using primer pairs covering the whole

\section{Figure 2}

Generation and characterization of the Tie2RAGE mouse line. (A) Tie2RAGE construct. Genomic RAGE DNA was cloned between the Tie2 promoter and enhancer. Gray boxes indicate RAGE exons; Roman numerals indicate $R A G E$ exon numbers. $E, E C o R I$ restriction enzyme site. (B) Southern blot analysis of DNA obtained from tail biopsies from WT and Tie2RAGE mice; EcoRI digestion releases a 2.2-kb DNA fragment from the Tie2RAGE transgene. (C) RT-PCR of different tissues derived from Tie2RAGE (Tie2) and WT mice analyzed for RAGE mRNA expression. WT indicates transgene-negative littermates. HPRT was used to demonstrate equal loading. (D) Immunohistology for RAGE protein in Tie2RAGE and WT kidney tissue. Brown staining indicates RAGE expression; magnification, $\times 400$. RAGE expression in kidneys of Tie2RAGE mice is evident in the endothelium of large and small vessels, while no RAGE protein could be detected in kidneys of healthy WT mice.
A 5

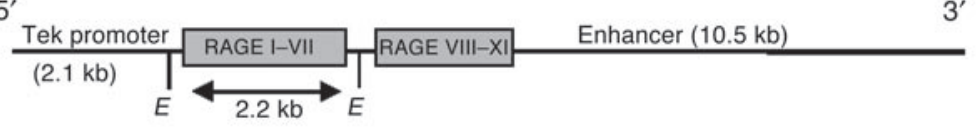

B

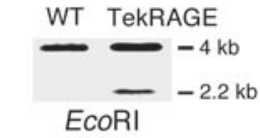

C Liver Kidney Spleen Lung Heart Brain Tek WT Tek WT Tek WT Tek WT Tek WT Tek WT

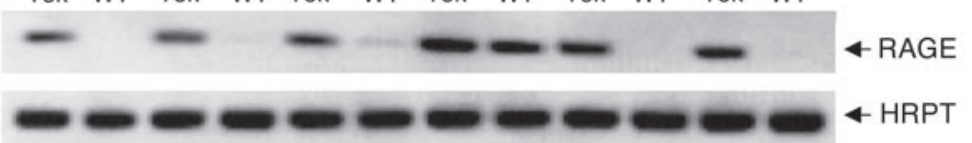

D
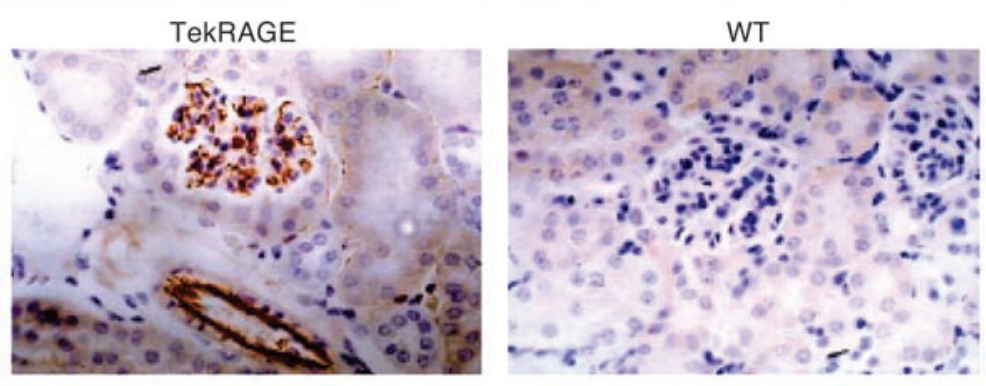


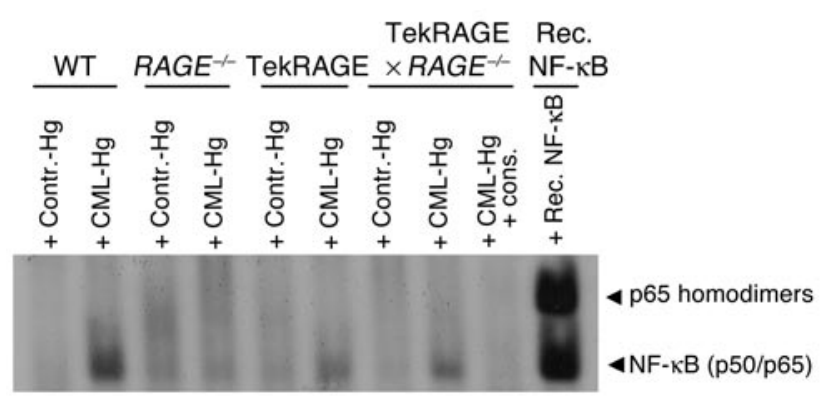

Figure 3

NF- $\mathrm{BB}$ inducibility in peripheral blood mononuclear cells of the various mouse strains. Six-month-old WT, RAGE ${ }^{-1-}$, Tie2RAGE, or Tie2RAGE $\times$ RAGE ${ }^{-/-}$mice received unmodified control hemoglobin (Contr.-Hg) or CML-modified hemoglobin (CML-Hg) $(1,000 \mu \mathrm{g} / \mathrm{mouse}$ at time point 0 , intraperitoneally). Six days later, mice were sacrificed and NF-KB-binding activity was determined in total blood. Recombi-

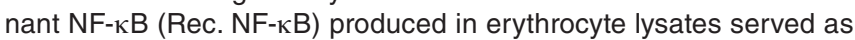
control for NF- $\mathrm{KB}$ binding. To confirm NF- $\mathrm{KB}$ binding, binding activity at 6 days was competed with a 160-fold molar excess of unlabeled consensus NF- $\kappa B$ oligonucleaotides (cons.). Arrowheads indicate

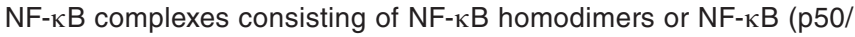
p65) heterodimers, respectively.

receptor to ensure expression of the entire molecule, and RAGE overexpression was quantified by real-time PCR (Taq Man). The full-length RAGE molecule was expressed in Tie2RAGE mice, and quantification demonstrated at least ten times more RAGE transcripts in kidney, spleen, liver, and brain of Tie2RAGE mice than in those of WT mice (data not shown). Renal tissue was subjected to immunohistology to demonstrate RAGE transgene expression in distinct cell types. RAGE expression in Tie2RAGE kidneys was restricted to the endothelium of large and small vessels, whereas RAGE protein could not be detected in WT tissue (Figure 2D).

$R A G E^{-/-}$and Tie2RAGE mice were viable and displayed normal reproductive fitness. No spontaneous disease development was observed in mice up to the age of 6 months; mice were housed under specific pathogen-free (SPF) conditions. Mice displayed normal macroscopic pathology and histopathology.

Because ligation of RAGE results in sustained activation of NF- $\mathrm{B}$ (25), electrophoretic mobility-shift assay (EMSA) was performed to define the extent of (carboxymethyl)lysine-mediated (CML-mediated) NF-KB inducibility in the different mouse mutants. WT, $R A G E^{-/-}$, Tie2RAGE, and Tie2RAGE $\times$RAGE $E^{-/-}$mice received a single intraperitoneal dose of $1,000 \mu \mathrm{g}$ CML-modified

\section{Figure 4}

$R A G E^{-/-}$and Tie2RAGE mice develop a normal immune response in $E A E$. Age- and sex-matched mice were sensitized against oligodendrocyte glycoprotein (MOG35-55) and were monitored for the onset of clinical signs on a daily basis (see Methods). (A) EAE response in WT and RAGE ${ }^{-1-}$ mice. WT indicates C57BL/6 $\times 129 /$ Sv mice. The mean clinical score represents a summary of two independent experiments each for WT and for RAGE-/- WT, filled squares; $R A G E^{-/-}$, open circles. (B) EAE response in WT and Tie2RAGE mice. WT mice used were transgene-negative littermates. The mean clinical score represents a summary of two independent experiments each for WT and for Tie2RAGE. WT, filled squares; Tie2RAGE, open triangles. The standard error of the mean is given $( \pm$ SEM), and $P<0.05$ was considered to be statistically significant. hemoglobin or control hemoglobin. Total blood was collected 6 days later and was subjected to NF-кB-specific EMSA. Prominent NF- $\kappa B-b i n d i n g$ activity induced by CML was observed in the blood of WT, Tie2RAGE, and Tie2RAGE $\times R A G E^{-/-}$mice and was absent from $R A G E^{-/-}$mice (Figure 3 ). These data confirm the lack

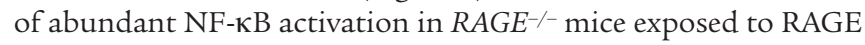
ligands. In contrast, Tie2RAGE mice responded with increased and perpetuated NF- $\mathrm{KB}$ activation after a single CML challenge and thus have intracellular signaling capabilities that mediate RAGEdependent NF- $\kappa$ B activation (Figure 3). Furthermore, Tie2-driven RAGE overexpression in hematopoietic and endothelial cells was sufficient to reconstitute CML-dependent NF- $\kappa \mathrm{B}$ inducibility in total blood of RAGE-deficient mice (Figure 3).

Normal adaptive immune responses in RAGE mutant mice. No difference was observed in the development of immunocompetent cells in WT and $R A G E^{-/-}$mice, as assessed by determination of the development of T cells in the thymus with flow cytometry as well as by comparison of the numbers of B and T cells in the spleen (data not shown). The experimental autoimmune encephalomyelitis (EAE) model (myelin oligodendrocyte glycoprotein [MOG] model) was selected as an autoimmune model to analyze the immune competence of RAGE mutant mice in vivo. This model allows study of the functionality of initiation of the adaptive immune response, inflammation, migration of immune competent cells, and tissue destruction. EAE was induced in $R A G E^{-/-}$, Tie2RAGE, and WT mice. $R A G E^{-/-}$mice developed typical EAE symptoms, and no significant difference was found by comparison of the mean clinical disease scores of WT and $R A G E^{-/-}$mice in various independent experiments, of which two are shown in Figure 4A. These results demonstrate that the initiation of the adaptive immune response, migration of immunocompetent cells, and destruction of myelin sheets leading to paralysis of RAGE mutant mice are comparable
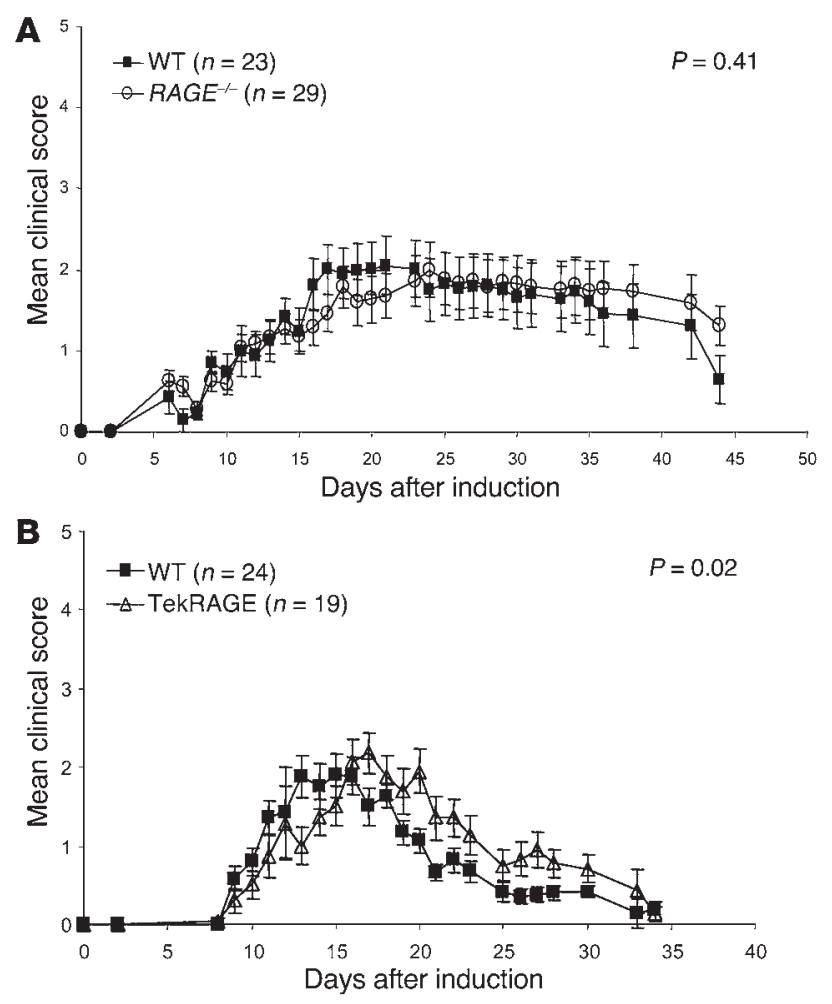

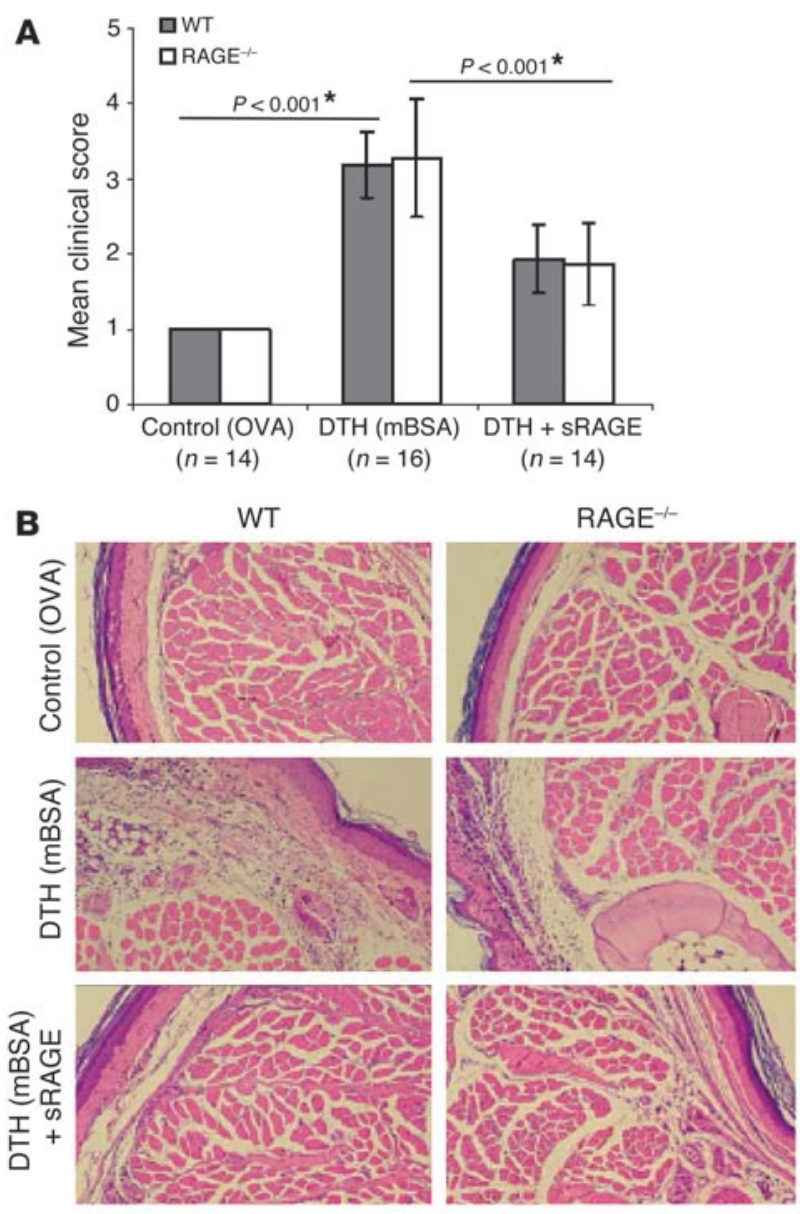

to those of WT mice. In contrast, the mean clinical EAE scores of WT and Tie2RAGE mice were statistically different $(P=0.02$; Figure $4 \mathrm{~B}$ ), indicating that amplification of EAE is promoted in mice overexpressing RAGE. Consistent with our results, in the myelin basic protein (MBP) model of EAE (a model most closely mimicking an acute initial episode of EAE), RAGE blockade via several approaches (see Discussion) reduced the intensity of the inflammatory cell infiltrate and symptomatology, although not the generation of a humoral or cell-mediated response to MBP (48).

Likewise, in the MOG model of EAE, RAGE-deficient mice did not show any abnormalities in various other adaptive immune responses in vitro and in vivo, including generation of alloreactive cytotoxic T cells in vitro, skin allograft rejection, graft-versus-host disease (GvHD), and antibody production against Pasteurella pneumotropica Jawetz NTC8141 (data not shown).

Reduction in DTH responses by sRAGE in RAGE $E^{-/-}$mice. Using a DTH model, we previously demonstrated a significant reduction of the inflammatory response in mice after application of sRAGE (37). One interpretation of these results would assign RAGE a central role as a mediator of inflammation in DTH. To test this hypothesis, we induced DTH in $R A G E^{-/-}$mice. However, $R A G E^{-/-}$mice developed the same inflammatory response as WT controls. The mean inflammation score, as assessed in two independent experiments, is shown in Figure 5A. Hematoxylin and eosin-stained footpad sections demonstrated inflammation and infiltration of immune-competent cells (Figure 5B). In addition, similar results were obtained with an ear-swelling DTH model (data not shown).

\section{Figure 5}

$R A G E^{-/-}$mice display normal inflammation in a model of DTH, and application of sRAGE blocks inflammation in DTH in WT and $R A G E^{-/-}$mice. Age- and sex-matched WT and $R A G E^{-/-}$mice were sensitized with mBSA. WT indicates C57BL/ 6 × 129/Sv mice. Control groups were challenged with ovalbumin (OVA), and DTH groups, with $\mathrm{mBSA}$. Mouse groups receiving SRAGE were pretreated by intraperitoneal injection of solvent or SRAGE 24 and 12 hours prior to and 6 and 12 hours after local challenge with mBSA. The DTH experiment was repeated three times and the DTH with sRAGE treatment was repeated two times with similar results $(\mathbf{A})$. The mean clinical inflammation score represents a summary of two independent experiments. Twenty-four hours after footpad injection, mice were subjected to clinical scoring (see Methods). Standard error is given ( \pm SEM), and $P<0.05$ was considered to be statistically significant $\left.{ }^{*}\right)$. WT, gray bars; $R A G E^{-/-}$, white bars. (B) Representative pictures of hematoxylin and eosin-stained footpad sections of experimental groups; magnification, $\times 400$.

Analysis of footpad homogenates for cytokine expression in inflammation by ELISA did not display differences in expression patterns of TNF- $\alpha$, IL-1 $\beta$, IL-6, and IFN- $\gamma$ in WT and $R A G E^{-/-}$mice (data not shown). As the RAGE gene has been deleted in $R A G E^{-/-}$mice, these data suggest that at least in this model, the effect of sRAGE is not explained by blocking ligand engagement of the membrane-bound form of RAGE (i.e., full-length RAGE).

This result was surprising, given previous studies showing that application of sRAGE reduced DTH responses in WT mice. We therefore tested whether treatment of $R A G E^{-/-}$mice with sRAGE would alter the inflammatory response in DTH. Indeed, application of sRAGE significantly blocked the inflammatory response in DTH in both WT and $R A G E^{-/-}$mice (Figure 5A; ${ }^{*} P<0.001$ ). Reduced inflammation in the presence of sRAGE was confirmed histologically (Figure 5B). The efficacy of sRAGE treatment in $R A G E^{-/-}$mice further provides support of the concept that the beneficial effects of sRAGE observed in DTH were not caused by prevention of ligand engagement of cell surface RAGE.

$R A G E^{-/-}$mice are protected from lethal septic shock. After testing several models for adaptive immune responses without detecting an obvious defect in $R A G E^{-/-}$mice, we studied the effect of RAGE on the innate immune response. For this purpose, a model of polymicrobial septic peritonitis, previously shown to be dependent on the innate immune response (49), was applied to $R A G E^{-/-}$mice. Multibacterial peritonitis was induced by cecal ligation and puncture (CLP) in WT and $R A G E^{-/-}$mice, and the survival from the septic challenge was monitored for up to 7 days (Figure 6A). The efficacy of CLP was confirmed 24 hours after CLP in selected mice by monitoring of the partial pressure of arterial oxygen $\left(\mathrm{PaO}_{2}\right)$ and the decrease in blood pressure and antithrombin III (AT III) serum levels as systemic markers of septicemia (Table 1). Up to $80 \%$ of the $R A G E^{-/-}$mice survived the septic shock, whereas WT mice were more susceptible to septic shock, as demonstrated by survival of $20 \%$ of the control group ( $P=0.001$; Figure $6 \mathrm{~A})$. Consistent with that finding, $R A G E^{-/-}$mice demonstrated a weaker decrease in blood pressure and AT III (Table 1). These differences were not due to the mixed background of $R A G E^{-1-}$ and WT mice, as CLP experiments were performed with a large number of mice and with $R A G E^{-/-}$mice and WT littermates after five backcrosses to $\mathrm{C} 57 \mathrm{BL} / 6$ mice (F5) with similar results (data not shown). Thus, the absence of RAGE apparently seems to protect mice from lethal multibacterial peritonitis. 

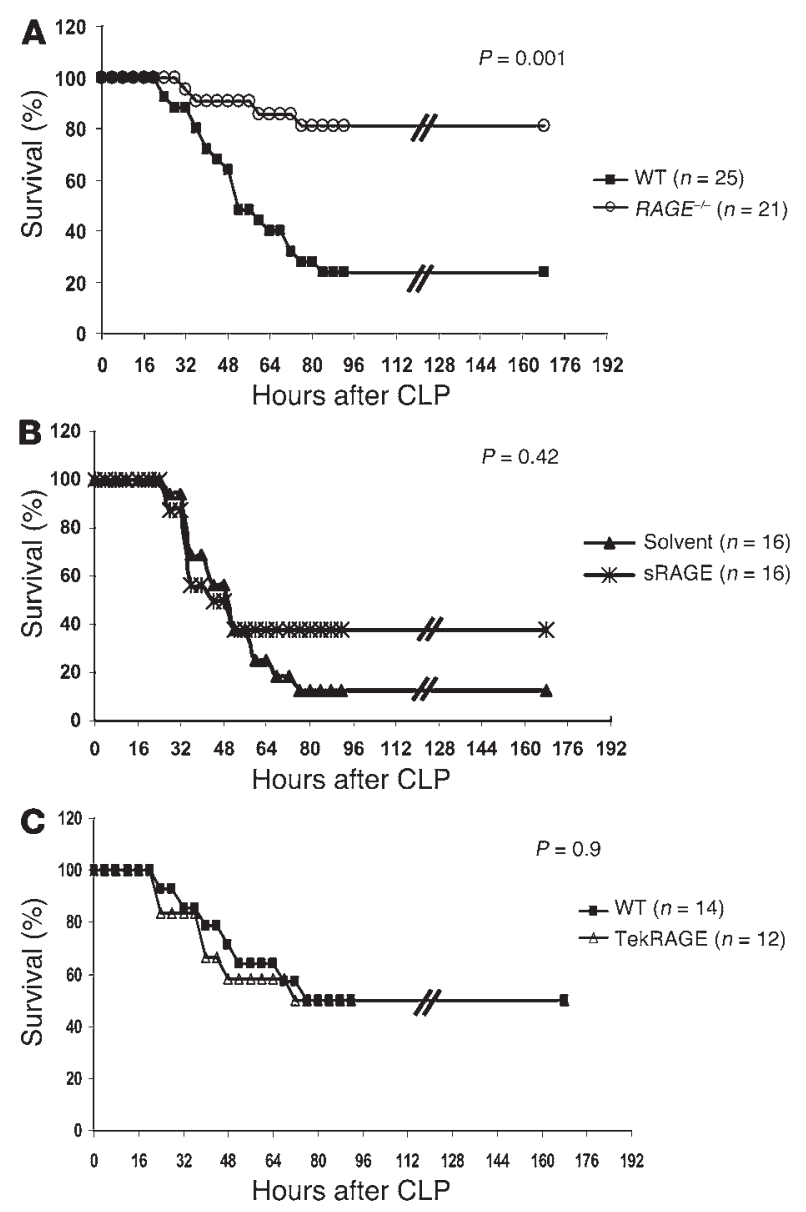

Next, C57BL/ 6 mice were subjected to CLP and one experimental group received repeated sRAGE treatments to evaluate the effect of sRAGE in multibacterial peritonitis and septic shock (Figure 6B). Administration of sRAGE slightly improved survival of the treated mouse group ( $40 \%$ survival) compared with the group receiving solvent only (17\% survival) (Figure 6B); however, in contrast to the RAGE deletion, this effect was not statistically significant $(P=0.42)$.

When CLP experiments were performed with WT and Tie2RAGE mice to investigate the effect of high initial RAGE expression in hematopoietic cells and the endothelium on the lethality of sepsis (Figure 6C), no difference in survival was seen after CLP in both mouse groups (50\% survival, WT and Tie2RAGE). Thus, initial excessive RAGE expression in hematopoietic and endothelial cells does not enhance the lethality of the CLP model.

To further define the role of RAGE in CLPdependent lethal septic shock, we crossed $R A G E^{-/-}$mice with Tie2RAGE transgenic mice. WT, $R A G E^{-/-}$, and Tie2RAGE $\times R A G E^{-/-}$were subjected to CLP and monitored for survival (Figure 7). Interestingly, $R A G E^{-/-} \times$ Tie2RAGE were as susceptible as WT mice to lethality after CLP (40\% survival), whereas more than $80 \%$ of $R A G E^{-/-}$littermates survived in the same experiment (Figure 7). These data indicate a pivotal role for RAGE expressed in hematopoietic and endothelial cells in mediating CLP-dependent death.

\section{Figure 6}

$R A G E^{-/-}$mice and WT mice treated with SRAGE are protected against septic shock induced by CLP. (A) Age- and sex-matched WT and $R A G E^{-/-}$mice were subjected to CLP or sham operation and were monitored for survival. WT indicates C57BL/ $6 \times 129 / \mathrm{Sv}$ mice. A summary of four repeated experiments is shown. One to two sham-operated mice were included in each single experiment (data not shown) and did not show overt signs of disease. WT, filled squares; $R A G E^{-/}$, open circles. (B) Therapeutic effect of SRAGE treatment. CLP was performed in ageand sex-matched C57BL/6 mice. Mice received repeated intraperitoneal injections of SRAGE or solvent (LPS-free $0.9 \% \mathrm{NaCl}$ ) immediately after CLP (150 $\mu \mathrm{g}$ sRAGE/mouse) and 6, 12, 24, and 36 hours thereafter (70 $\mu \mathrm{g}$ sRAGE/mouse). Two repeated experiments are summarized. WT treated with solvent, filled triangles; WT treated with sRAGE, asterisks. (C) Age- and sex-matched WT and Tie2RAGE mice were subjected to CLP and were monitored for survival. WT indicates transgene-negative littermates. A summary of two repeated experiments is shown. One to two sham-operated mice were included in each single experiment (data not shown) and did not show overt signs of disease. WT, filled squares; Tie2RAGE, open triangles.

Notably, neither the number of inflammatory cells (Table 2) nor the cytokine levels (data not shown) differed significantly in WT and $R A G E^{-/}$mice that underwent CLP. In order to further address mechanisms by which loss of RAGE reduces lethality in septicemia, we collected peritoneum, one of the target tissues of CLP, and studied the inflammatory response therein. Histological examination showed reduced numbers of inflammatory cells adherent to the peritoneum of $R A G E^{-1-}$ mice after CLP compared with that of WT mice (Figure $8 \mathrm{~A} ; P=0.001)$. While WT mice displayed an increase in cells adhering to the peritoneum after CLP (Figure 8A; WT "sham") compared with CLP, $P<0.001$ ), no increase in cell adhesion after CLP was observed in the peritoneum of $R A G E^{-/-}$mice (Figure 8A; $P=0.059$ ).

When EMSA for NF- $\kappa$ B-binding activity was performed with a protein extract derived from the peritoneum, only WT mice demonstrated a strong increase in NF- $\kappa \mathrm{B}$-binding activity in response to CLP (Figure $8 \mathrm{~B}$ ). In contrast, there was no significant upregulation of NF-KB-binding activity in the peritoneum of $R A G E^{-/-}$mice that underwent CLP. Similar results were obtained in lungs from mice that underwent CLP (Figure 8C). NF- $\mathrm{BB}$ activation was induced much more strongly in lungs of WT mice than in lungs of $R A G E^{-/-}$ mice (Figure $8 \mathrm{C}$ ), indicating that the lack of excessive NF- $\mathrm{\kappa B}$ activation in $R A G E^{-/-}$mice might contribute to their reduced mortality.

\section{Discussion}

RAGE has been identified as a central signal transduction receptor mediating long-lasting NF- $\mathrm{BB}$ activation in various cell types,

\section{Table 1}

$\mathrm{PaO}_{2}$, median arterial blood pressure, and AT III plasma levels in WT and $R A G E^{-/-}(\mathrm{R})$ mice before and 24 hours after CLP

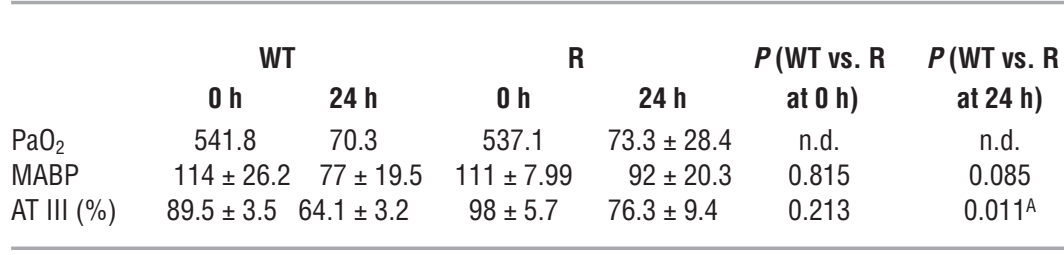

AP $<0.05 .0$ h, before CLP; 24 h, 24 hours after CLP; MAPB, median arterial blood pressure; n.d., not determined. 


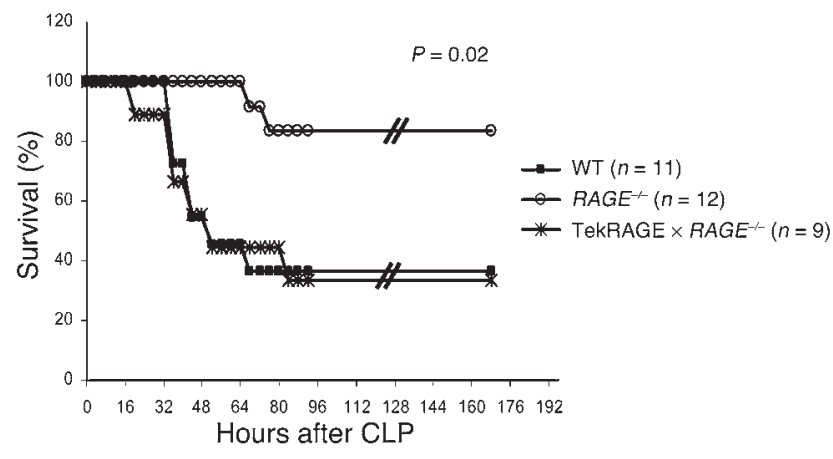

Figure 7

Rescue of RAGE expression in hematopoietic cells and the endothelium abolishes protection from septic shock independently of phagocytosis after CLP. Age- and sex-matched WT, $R A G E^{-/-}$, and Tie2RAGE $\times$ $R A G E^{-/-}$mice were subjected to CLP and were monitored for survival. Additionally, one to two sham-operated mice were included in each single experiment (data not shown). WT indicates C57BL/6 $\times 129 / \mathrm{Sv}$ mice. A summary of two repeated experiments is shown. WT, filled squares; $R A G E^{--}$, open circles; Tie2RAGE $\times R A G E^{-/}$, asterisks.

including mononuclear phagocytes and vascular endothelium (25). Its physiological role in inflammation was emphasized mainly by two key findings: (a) an increased expression of RAGE in inflammatory lesions of various diseases $(20-24,28)$ and (b) the capacity of the soluble receptor and anti-RAGE $\mathrm{F}(\mathrm{ab})_{2}$ fragments to block ongoing enterocolitis as well as the onset of DTH responses (37). Here we report the novel and surprising finding that $R A G E^{-/-}$mice can mount normal adaptive immune responses. After mice were infected with $P$. pneumotropica, antibody subtypes and titers were comparable in the blood of $R A G E^{-/-}$and of WT mice (our unpublished observations). In addition, transfer of alloreactive $\mathrm{T}$ cells into irradiated $R A G E^{-/-}$mice caused normal GvHD (our unpublished observations). Finally, induction of EAE and DTH led to comparable onset and progression of the disease. These results indicate that sRAGE has effects other than simply blocking cell surface RAGE function. This view is further strengthened by our finding that application of sRAGE reduced DTH responses to the same extent in both $R A G E^{-/-}$and WT mice.

This result was surprising, as RAGE ligands such as S100 proteins are generated in DTH. Moreover, activation of NF- $\mathrm{KB}$ was comparable in WT and $R A G E^{-/-}$mice after DTH and was reduced to the same extent in both mouse strains after treatment with sRAGE (our unpublished observations). One explanation is that indeed NF- $\mathrm{KB}$ activation and inflammation in DTH occur independently of transmembrane RAGE. The inflammatory mediators scavenged by sRAGE additionally interact with cellular structures other than RAGE, as sRAGE blocks inflammation in $R A G E^{-/-}$mice. It is also possible that compensatory mechanisms have evolved in $R A G E^{-1-}$ mice, leading to enhanced expression and/or function of other putative cell surface interaction sites for RAGE ligands. $R A G E^{-/-}$mice, therefore, may provide a suitable model for outlining novel pathways linked to the inflammatory response.

However, blocking $\mathrm{F}(\mathrm{ab})_{2}$ fragments derived from anti-RAGE IgG reduces the inflammatory response in MOG or MBP-induced EAE (48). Furthermore, expression of dominant negative RAGE (a mutant form of RAGE lacking the cytosolic domain and capacity of signal transduction) selectively in $\mathrm{CD}^{+} \mathrm{T}$ cells also reduces the inflammatory reaction in EAE (48). Together with the observa- tion that the outcome of EAE is worsened in Tie2RAGE mice with overexpression of RAGE in the vasculature, these data indicate that RAGE is involved in the perpetuation but not the initiation of EAE and thus might explain the differences among the different models. Differences between previous results and those shown here may be explained further by the different experimental conditions and/or by the induction of compensatory pathways in RAGE-deficient mice. However, the reduction of DTH by sRAGE in $R A G E^{-/-}$mice "argues against" this explanation, unless deletion of RAGE caused upregulation of other cellular binding sites for RAGE ligands that emerge with a more prominent role in the complete absence of RAGE. The efficacy of sRAGE in the DTH response in $R A G E^{-/-}$mice indicates that SRAGE is a tool for understanding ligands capable of binding to RAGE but also potentially to other binding sites. The possible relevance of other effector molecules' mediating sRAGE binding opens the question of whether these putative binding sites share structurally significant homologies with the ligand-binding domain of RAGE. RAGE is capable of recognizing various ligands characterized by $\beta$-sheets and fibril formation (50). Taken together with the data presented in the CLP model of septic shock, this puts RAGE in the group of PRRs important for innate immune responses $(1-6,44)$. Even though there is no doubt that blocking anti-RAGE $\mathrm{F}(\mathrm{ab})_{2}$ fragments target this receptor, it cannot presently be excluded that they also recognize a tertiary structure similar to the PRR ligand-binding domain of RAGE. Studies looking at other molecules distinct from RAGE with a similar tertiary structure of their ligand-binding domain are currently underway.

Whereas initiation and perpetuation of inflammation was normal in $R A G E^{-/-}$mice in models addressing predominantly the adaptive immune responses, a different result was obtained in CLP-mediated sepsis, a model largely dependent on the innate immune response. In contrast to WT mice, most $R A G E^{-/-}$mice survived the septic shock. The contribution of RAGE to the outcome of survival was demonstrated by crossing of transgenic Tie2RAGE mice on the $R A G E^{-1-}$ genotype. The resulting animals were susceptible to septic shock in the same way as WT mice. Ongoing studies indicate that hematopoietic and endothelial cells might be the most important sites of RAGE expression in CLP, as transplantation of RAGE-expressing cells into $R A G E^{-/-}$mice reduced survival (our unpublished observations). In this context, however, it is noteworthy that overexpression of RAGE did not enhance lethality in CLP (or modulated adaptive immune responses), indicating

\section{Table 2}

Total blood counts of WT and RAGE--- mice 24 hours after CLP

\begin{tabular}{|c|c|c|c|}
\hline & WT & $\mathbf{R}$ & $P$ value \\
\hline \multicolumn{4}{|c|}{ Total leukocytes } \\
\hline Control & 5.0 cells/nl & 8.1 cells $/ \mathrm{nl}$ & 0.172 \\
\hline CLP & 1.15 cells/nl & $1.14 / \mathrm{nl}$ & 0.974 \\
\hline \multicolumn{4}{|c|}{ Neutrophils } \\
\hline Control & 0.075 cells $/ \mathrm{nl}$ & 0.11 cells/nl & 0.38 \\
\hline CLP & $0.022 / \mathrm{nl}$ & 0.035 cells/nl & 0.25 \\
\hline \multicolumn{4}{|c|}{ Lymphocytes } \\
\hline Control & $70 \%$ & $62.5 \%$ & 0.535 \\
\hline CLP & $37.5 \%$ & $30 \%$ & 0.179 \\
\hline \multicolumn{4}{|l|}{ Monocytes } \\
\hline Control & $21 \%$ & $30 \%$ & 0.43 \\
\hline CLP & $52 \%$ & $56 \%$ & 0.58 \\
\hline
\end{tabular}


A

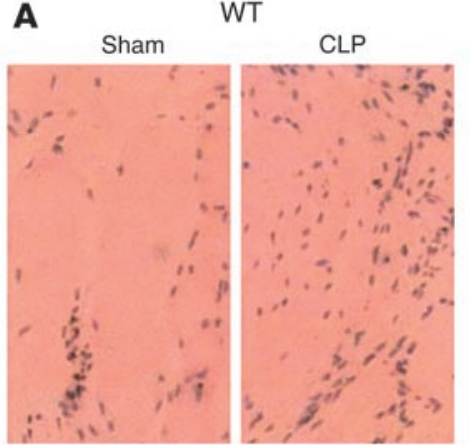

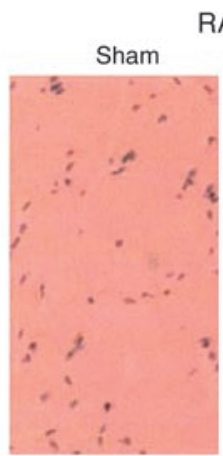

RAGE $^{-1}$

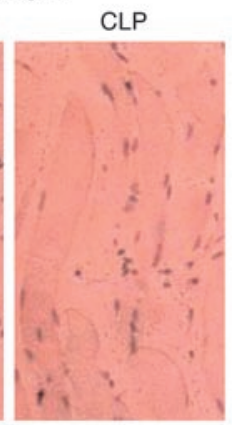

$P<0.001$
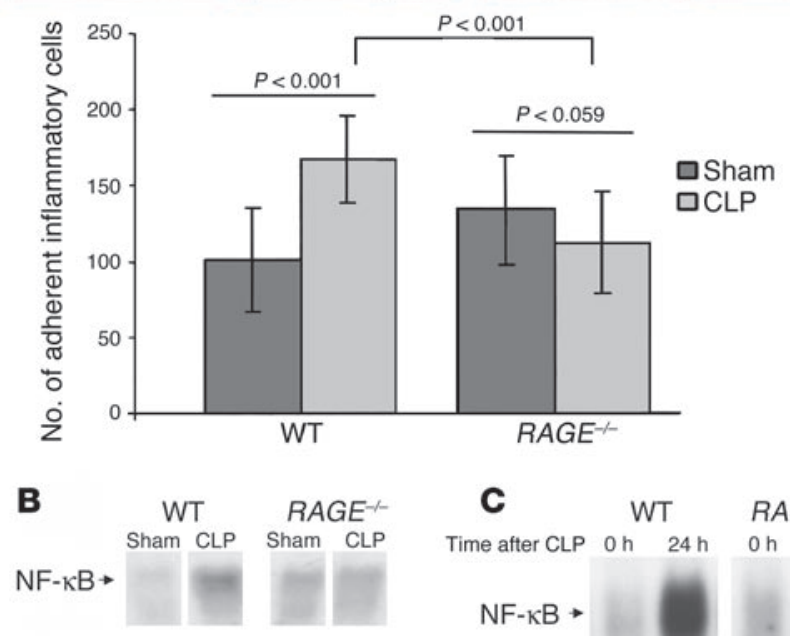

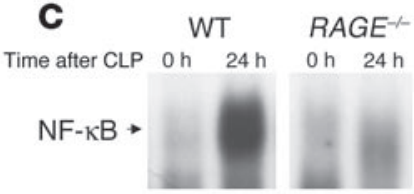

that endogenous RAGE is sufficient to generate the full clinical course of septicemia. Likewise, treatment of Tie2RAGE mice with CML did not result in the expected "superinduction" of NF-кB but in a slightly weaker increase in NF-кB-binding activity than that in WT mice (Figure 3). These data and the observation that healthy $R A G E^{-/-}$mice have a slightly proinflammatory phenotype, as indicated by increased C-reactive protein (our unpublished observations), a slight increase in basal NF-кB-binding activity (Figure 8, $\mathrm{B}$ and $\mathrm{C}$ ), and elevated cytokine levels suggest that RAGE might also be involved in the regulation of anti-inflammatory processes (our unpublished observations). The ability of tie2-driven RAGE overexpression to activate NF- $\mathrm{KB}$ in $R A G E^{-/-}$mice upon engagement of RAGE excludes the possibility that Tie2RAGE is simply serving as a "decoy receptor" or compensates for shedding of the receptor upon activation.

The data presented here implicate that RAGE-dependent activation of NF- $\kappa \mathrm{B}$ plays a central role in modulating mortality after CLP. While WT, Tie2RAGE, and Tie2RAGE $\times R A G E^{-/-}$mice demonstrated strong NF- $\kappa$ B activation associated with high CLPmediated lethality, $R A G E^{-/-}$mice were characterized by a reduced activation of NF-KB in septic shock target organs (lung, peritoneum, and blood) and increased survival. Remarkably, recently described $C D 40^{-/-}$mice also demonstrate attenuated activation of NF- $\mathrm{B}$, delayed death, and improved survival after CLP (51), further suggesting a causal relation between altered NF- $\mathrm{\kappa B}$ regulation and mortality after polymicrobial sepsis.

The RAGE ligand HMGB1 has recently been identified as a late mediator of lethality in sepsis (45). Blocking HMGB by ethyl

\section{Figure 8}

Inflammatory cell adhesion on the peritoneum and NF-кB activation after CLP is reduced in $R A G E^{-/-}$mice. Age- and sex-matched WT and $R A G E^{-1-}$ mice were sham-operated (Sham) or were subjected to CLP. WT indicates C57BL/6 $\times 129 / S v$ mice. Twenty-four hours after sham operation or CLP, peritoneum was harvested for histology or isolation of nuclear proteins for EMSA. Experiments were repeated three times with similar results. (A) Representative pictures of hematoxylin and eosin-stained peritoneum sections from experimental groups showing adherent inflammatory cells; magnification, $\times 400$. Cells in visual fields of serial sections of peritoneum were counted using a microscope, and the results were summarized and analyzed statistically. The standard error is given ( \pm SEM), and $P<0.05$ was considered to be statistically significant $\left({ }^{*}\right)$. WT, dark gray bars; $R A G E^{--}$, light gray bars. (B) Representative EMSA for NF-KB-binding activity in peritoneum derived from WT and $R A G E^{-/-}$mice 24 hours after sham operation or CLP. (C) Representative EMSA for NF-кB-binding activity in lungs derived from WT and $R A G E^{-1-}$ mice before $(0 \mathrm{~h})$ and 24 hours after (24 h) CLP.

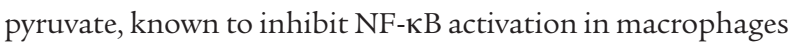
in vitro (52), prevented lethality in mice with established lethal sepsis and systemic activation (52). Thus, the lack of HMGB1-RAGE interactions in $R A G E^{-/-}$mice is likely to contribute to their improved survival after CLP. The observation that the competition for binding of ligand to RAGE by sRAGE was much less effective in reducing lethality than was RAGE deletion (Figure 6), however, indicates that additional mechanisms might be operative.

RAGE has recently been identified as counter-receptor of the $\beta_{2}$-integrin Mac-1 able to mediate leukocyte adhesion (53). One mechanism by which excessive NF- $\mathrm{\kappa B}$ activation might affect the outcome of disease is by amplifying expression of both RAGE and other adhesive receptors such as ICAM-1 and VCAM-1, thus promoting leukocyte recruitment. Consistent with this finding, the peritoneum of $R A G E^{-/-}$mice undergoing CLP demonstrated significantly less adhesion of inflammatory cells (Figure 8A), while the total number of inflammatory cells was the same in total blood counts of WT and $R A G E^{-/-}$mice (Table 2). CLP-challenged $R A G E^{-/-}$mice presented with higher AT III levels. The difference observed was highly significant 24 hours after CLP (WT vs. $R A G E^{-/-}, P=0.011$; Table 1 ). AT III is a marker of excessive activation of coagulation in septicemia. In addition, one might speculate that the moderate inflammation observed in $R A G E^{-/-}$mice (our unpublished observations) activates cellular defense mechanisms that resist the polymicrobial challenge. Consistent with this hypothesis, CLP mice treated with anti-TNF- $\alpha$ have been reported to show a tendency toward a worsened outcome (54).

The studies in $R A G E^{-/-}$mice presented here suggest that RAGE participates in inflammation in the CLP model of innate immunity. The situation in the adaptive immune response may be more complex, however, as the presence of potent compensatory mechanisms modulating cellular effector sites for RAGE ligands in that setting has not been ruled out. The data presented are not only useful for dissecting at which levels adaptive and innate immune responses may diverge, they also offer novel options for the development of RAGE inhibitors for treating septicemia. The central role of RAGE in CLP and the demonstrated lack of an effect in adaptive immune responses using $R A G E^{-/-}$mice, at least under 
these experimental conditions, present novel insights into distinct pathways involved in both types of immune responses.

\section{Methods}

\section{Generation of $\mathrm{RAGE}^{-/-}$mice and Tie2RAGE mice}

Generation of $\mathrm{RAGE}^{-/-}$mice. The RAGE targeting construct and the generation of $R A G E^{-/-}$mice have been described in detail elsewhere $(55,56)$. Animals used in the described experiments were from F2 or F5 backcrosses onto the C57BL/6 genetic background.

Generation of Tie2RAGE transgenic mice. The $2.1-\mathrm{kb}$ promoter and $10.5-\mathrm{kb}$ first intron sequences from the murine Tie2 gene were cut from the vector pT2HlacZpA11.7 with HindIII and XbaI/NotI (kindly provided by T.N. Sato, Harvard Medical School, Boston, Massachusetts, USA) and were cloned into pBSK (Stratagene, Heidelberg, Germany). The resulting plasmids were called pTie22.5 and pTie2-10.5, respectively (46). A 500-kb MboII-digested partial genomic RAGE fragment was cloned into the HindIIIdigested pTie2-2.5 plasmid. The 3.5-kb AvvII-digested part of the RAGE DNA was cloned into the resultant plasmid to complete the genomic RAGE sequence. The Tie2 enhancer was released from pTie2-10.5 by XmaI/ClaI and NotI digestion and was introduced into the RAGE-containing construct. Tie2RAGE mice were generated by pronuclear injection of the transgenic construct into fertilized eggs of C57BL/ $6 \times$ DBA/2 F1 mice. Founder mice were tested by Southern blot analysis according to standard protocols. Heterozygous Tie2RAGE mice were used in all experiments.

$R A G E^{-1-}$ mice were mated to Tie2RAGE mice to reconstitute RAGE expression in hematopoietic and endothelial cells. The resulting Tie2RAGE $\times R A G E^{-/-}$mice were genotyped by Southern blot analysis. Mice were maintained in SPF housing conditions. Procedures in this study were approved by the Animal Care and Use Committee at the Regierungspräsidium Karlsruhe, Germany.

\section{Analysis of RAGE expression in mutant mice}

RT-PCR was used to evaluate RAGE expression at the mRNA level in $R A G E^{-/-}$and Tie2RAGE mice. RNA from diverse tissues was prepared using an RNA isolation kit (RNAeasy, Qiagen, Hilden, Germany) and was transcribed into cDNA. Primers used were as follows: extracellular RAGE domain forward primer, $5^{\prime}$ AACACAGGAAGAACTGAAGCTTGG-3', and reverse primer, 5'-CTTTGCCATCGGGAATCAGAAGTT-3'; and hypoxanthine guanine phosphoribosyl transferase (HPRT) forward primer, $5^{\prime}$ GTTGGATCAAGGCCAGACTTTGTT-3', and reverse primer, 5'GAGGGTAGGCTGGCCTATAGGCT-3'. The amplification cycles were as follows: for RAGE, one cycle of $95^{\circ} \mathrm{C}$ for 300 seconds, then 28 cycles of $95^{\circ} \mathrm{C}$ for 60 seconds, $62^{\circ} \mathrm{C} 30$ seconds, and $72^{\circ} \mathrm{C} 60$ seconds, followed by one cycle of $72^{\circ} \mathrm{C}$ for 600 seconds; for HPRT, one cycle of $94^{\circ} \mathrm{C}$ for 300 seconds, and 37 cycles of $94^{\circ} \mathrm{C} 30 \mathrm{sec}-$ onds, $60^{\circ} \mathrm{C}$ for 20 seconds, and $72^{\circ} \mathrm{C}$ for 40 seconds.

For evaluation of RAGE expression at the protein level, Western blot analysis and immunohistology was used. For Western blot analysis, proteins from "snap-frozen" mouse lungs were homogenized in $20 \mathrm{mM}$ Tris-HCl, pH 7.4, $100 \mathrm{mM} \mathrm{NaCl}, 1.5 \%$ NP-40, 10 mM EDTA, $2 \mathrm{mM}$ PMSF, and $0.5 \mathrm{mM}$ DTT, and were extracted. SDS gel electrophoresis, blotting, and signal detection was performed according to standard protocols (57) using the SuperSignal substrate (Pierce, Rockford, Illinois, USA). Polyclonal anti-human RAGE extracellular domain (1:3,000 dilution) was used as the primary antibody. This antibody was obtained by immunization of a rabbit with peptide derived from the extracellular RAGE domain (peptide sequence, CKGAPKKPPQRLEWKL). Rabbit serum was purified using protein $G$ and was tested for specificity in Western blots in comparison with other antibodies against human RAGE. Similar signals were detected for different antibodies against RAGE. For signal detection, horseradish peroxidase-conjugated anti-rabbit (Amersham Bioscience, Freiburg, Germany) was utilized.

For immunohistology, mouse organs were fixed in $4 \%$ neutral buffered formaldehyde and paraffin-embedded, and 5- $\mu \mathrm{m}$ sections were cut. RAGE proteins were detected using goat anti-human RAGE at a dilution of 1:3,000 (kindly provided by Merck, Sharpe \& Dohme, Essex, United Kingdom), and were visualized with a commercial ABC-peroxidase technique (Vectorstain Elite Kit PK-6105; ALEXIS Deutschland GmbH, Grünberg, Germany) according to the manufacturer's protocol.

\section{Model of EAE}

Two- to four-month-old mice were sensitized by subcutaneous injection of $200 \mu \mathrm{g}$ MOG peptides 35-55; German Cancer Research Center, Heidelberg, Germany [ref. 58]) in incomplete Freund's adjuvant (Sigma-Aldrich, Deisenhofen, Germany) containing $2 \mathrm{mg} / \mathrm{ml}$ Mycobacterium tuberculosis (Difco BD Bioscience, Heidelberg, Germany) and subsequent intraperitoneal injection of $200 \mathrm{ng}$ pertussis toxin (Merck Calbiochem, Darmstadt, Germany) at the day of sensitization and 48 hours later. Mice were monitored by experimenters "blinded" to the identity of different mouse groups for clinical signs 5-7 days per week for up to 60 days. The clinical grading system used was as follows: grade 0 , normal mouse, no overt signs of disease; grade 1, limp tail or hind limb weakness but not both; grade 2, limp tail and hind limb weakness; grade 3, partial hind limb paralysis; grade 4, complete hind limb paralysis; and grade 5, death by EAE; sacrifice according to the animal protection law.

\section{Model of DTH reaction}

Two- to four-month-old mice were sensitized by subcutaneous injection over the left inguinal lymph node of $100 \mu \mathrm{l}$ of an emulsion containing $25 \mathrm{mg} / \mathrm{ml}$ methylated BSA (mBSA; SigmaAldrich), $0.9 \% \mathrm{NaCl}, 50 \mathrm{mg} / \mathrm{ml}$ dextran $\left(5 \times 10^{6}\right.$ to $40 \times 10^{6}$ dalton molecular weight; Sigma-Aldrich), and 50\% incomplete Freund's adjuvant (Sigma-Aldrich). After 3 weeks, the left plantar hind paw was injected subcutaneously with $50 \mu \mathrm{l}$ of $0.4 \mathrm{mg} / \mathrm{ml} \mathrm{mBSA}$ in $0.9 \% \mathrm{NaCl}$. The control group received an injection with $50 \mu \mathrm{l}$ of $0.4 \mathrm{mg} / \mathrm{ml}$ ovalbumin (control peptide). Where indicated, mice were pretreated by intraperitoneal injection of $100 \mu \mathrm{g}$ sRAGE dissolved in LPS-free $0.9 \% \mathrm{NaCl}$ at 24 and 12 hours prior to and 6 and 12 hours after local challenge with mBSA (37). Control groups received solvent at the same time points. Twenty hours after food pad injection with mBSA, mice were assigned clinical scores by two investigators "blinded" to sample identity. The grading system for clinical assessment of DTH was as follows: 1 , absence of inflammation; 2 , slight rubor and edema; 3 , moderate rubor and edema with skin wrinkles; 4 , severe rubor and edema without skin wrinkles; and 5 , severe rubor and edema with toe spreading. Afterward, mice were sacrificed and their feet were fixed in $4 \%$ formalin and decalcified, and sections $5 \mu \mathrm{m}$ in thickness were cut and were stained with hematoxylin and eosin according to standard protocols.

\section{$C L P$}

CLP was performed as described previously $(49,59,60)$. In brief, mice 2-6 months old were anesthetized by intraperitoneal admin- 
istration of $75 \mathrm{mg} / \mathrm{kg}$ Ketanest (Parke-Davis, Berlin, Germany) and $16 \mathrm{mg} / \mathrm{kg}$ Rompun (Bayer AG, Leverkusen, Germany) in 0.2 $\mathrm{ml}$ sterile pyrogen-free saline (Braun AG, Melsung, Germany). The cecum was exposed through a $1.0-$ to $1.5-\mathrm{cm}$ abdominal midline incision and was subjected to a $50-80 \%$ ligation of the distal half followed by a single puncture with a 23 -gauge needle. A small amount of stool was expelled from the puncture to ensure patency. The cecum was replaced into the peritoneal cavity and the abdominal incision was closed by layers with 5/0 Prolene thread (Ethicon, Norderstedt, Germany). No antibiotics were administered in this model. For sham-operated mice, which served as control in each experiment, the cecum was mobilized but no ligation and puncture was performed. For experiments investigating the therapeutic effect of sRAGE after CLP, the C57BL/ 6 mice used were purchased from Wiga (Hannover, Germany). Where indicated, sRAGE was administered by intraperitoneal injection immediately after CLP $(150 \mu \mathrm{g} /$ mouse) and 6, 12, 24, and 36 hours thereafter (70 $\mu \mathrm{g} /$ mouse). Control groups received the same volume (50-180 $\mu \mathrm{l})$ of LPS-free $0.9 \% \mathrm{NaCl}$. CLP was performed by researchers "blinded" to the identity of the treatment group. Survival after CLP was assessed four to six times a day for at least 7 days. Blood pressure was measured with femoral manometric catheters in anesthetized mice 24 hours after CLP.

For harvesting of tissues and organs for histopathology and NF-кB determination, mice were deeply anesthetized by intraperitoneal injection of $30 \mu \mathrm{l}$ avertin per gram body weight (stock: $1 \mathrm{~g}$ tribromethanol and $620 \mu \mathrm{l} 2$-methyl-1-butanol; $180 \mu \mathrm{l}$ of stock per $10 \mathrm{ml} 0.9 \% \mathrm{NaCl}) 24$ hours after CLP. Tissues and organs were fixed in $4 \%$ formalin and sections $5 \mu \mathrm{m}$ in thickness were cut and were stained with hematoxylin and eosin according to standard protocols. Kidney, lung, liver, heart, spleen, and peritoneum were subjected to histopathology. Infiltrated inflammatory cells in the peritoneum were counted using a microscope. Peritoneum, lungs, and total blood to be used for EMSA were harvested 24 hours after CLP and were immediately "snap-frozen" in liquid nitrogen.

\section{EMSA}

Nuclear proteins from "snap-frozen" mouse tissues were isolated as described in detail elsewhere (25). When NF-кB-binding activity was studied in total blood, blood collected from the retrobulbar region was dropped directly into the same volume of cold buffer A (10 mM HEPES-KOH, pH 7.9, at $4^{\circ} \mathrm{C}, 1.5 \mathrm{mM} \mathrm{MgCl}_{2}$, $10 \mathrm{mM} \mathrm{KCl}, 0.5 \mathrm{mM}$ DTT, $0.2 \mathrm{mM}$ PMSF, and $0.6 \% \mathrm{NP}-40)$ and was mixed thoroughly. Blood was homogenized by being passed five times through a 20 -gauge needle fitted to a syringe and by being centrifuged for 30 seconds at $700 \mathrm{~g}$ at $4^{\circ} \mathrm{C}$ to remove tissue debris. The supernatant was incubated on ice for 10 minutes and was centrifuged for 5 minutes at $11,000 \mathrm{~g}$ at $4^{\circ} \mathrm{C}$. The supernatant was discarded and the nuclear pellet was resuspended in $100 \mu \mathrm{l}$ of buffer B (25\% glycerol, $20 \mathrm{mM}$ HEPES-KOH, pH 7.9, at $4{ }^{\circ} \mathrm{C}$, $420 \mathrm{mM} \mathrm{NaCl}, 1.5 \mathrm{mM} \mathrm{MgCl}_{2}, 0.2 \mathrm{mM}$ EDTA, $0.5 \mathrm{mM}$ DTT, 0.2 $\mathrm{mM}$ PMSF, $2 \mathrm{mM}$ benzamidine, and $5 \mathrm{mg} / \mathrm{ml}$ leupeptin) and was incubated on ice for 20 minutes. Cellular debris were removed by 2 minutes of centrifugation at $4^{\circ} \mathrm{C}$ and the supernatant was "quick-frozen" at $-80^{\circ} \mathrm{C}$. Nuclear extracts were assayed for transcription factor-binding activity using the NF- $\kappa \mathrm{B}$ consensus sequence 5'-AGTTGAGGGGACTTTCCCAGGC-3'. Specificity of binding was ascertained by competition with a 160 -fold molar excess of unlabeled consensus oligonucleotides and, where indicated, by comparison with binding of recombinant NF- $\mathrm{BB}$ pre- pared in erythrocyte lysate as described elsewhere (61). ProteinDNA complexes were separated from unbound DNA probe by electrophoresis through $5 \%$ native polyacrylamide gels containing $2.5 \%$ glycerol and $0.5 \times$ TBE. Gels were dried and exposed to $x$-ray film (Amersham Pharmacia, Freiburg, Germany) for 48-60 hours at $-80^{\circ} \mathrm{C}$ with intensifying screens.

\section{ELISA}

Tissue homogenates, plasma, and peritoneal lavage fluid were subjected to ELISA for determination of IL-1 $\beta$, IL-6, and TNF- $\alpha$ content. ELISA kits were purchased from R\&D System $\mathrm{GmbH}$ (Wiesbaden-Nordenstadt, Germany).

\section{Statistical analysis}

Where indicated, values of experimental groups are given as mean, with bars showing the standard error of the mean (SEM). The means of groups were compared by analysis of variance using Student's $t$ test. A probability $P<0.05$ was considered to be statistically significant.

Statistical analysis of time-dependent scores was performed by using generalized estimating equations. Covariates tested were group and experiment. The time dependency of repeated scores of individuals was modeled using a first-order autoregressive time series model. A local regression model was used to estimate the time-dependent mean score value. In addition, 95\% confidence limits of the mean score were computed.

Figures 5, A-C, and 6 show the Kaplan-Meier estimates of groupwise survival distributions. The log-rank test was used to compare two or more survival distributions. A result was denoted as statistically significant if the $P$ value of its corresponding test statistic was $5 \%$ or less. All statistical computations were performed using the statistical software package R, version 1.8 (62).

\section{Acknowledgments}

The work was supported by the Sonderforschungsbereich 405 (Deutsche Forschungsgemeinschaft [DFG], P.P. Nawroth and B. Arnold) and DFG Na 138 (P.P. Nawroth) and by the European Commission QLG1-CT-1999-00202 grant to G.J. Hämmerling. We thank N. Michel, G. Kübelbeck, S. Schmitt, A. Klevenz, S. Schmitt, G. Hollmann, E. Rezavandy, S. Paljevic, C. Schumann, and D. Slocum for excellent technical assistance; T.N. Sato for the Tie2 regulatory elements; K. Rajewsky (CBR Institute for Biomedical Research, Harvard Medical School, Boston, Massachusetts, USA) for the Cre deleter mouse line; Merck Sharpe \& Dohme for anti-human RAGE; and Axel Benner (DKFZ [German Cancer Research Center] Heidelberg, Germany) for his support in statistical analysis.

Received for publication April 18, 2003, and accepted in revised form March 26, 2004.

Address correspondence to: Peter P. Nawroth, Department of Medicine I, Im Neuenheimer Feld 410, 69120 Heidelberg, Germany. Phone: 49-6221-568600; Fax: 49-6221-565226; E-mail: peter_nawroth@med.uni-heidelberg.de.

Birgit Liliensiek, Markus A. Weigand, and Angelika Bierhaus contributed equally to this work.

Peter P. Nawroth and Bernd Arnold are co-senior authors. 
1. Zhang, G., and Ghosh, S. 2001. Toll-like receptormediated NF-KB activation: a phylogenetically conserved paradigm in innate immunity. J. Clin. Invest. 107:13-19.

2. Medzhitov, R., Preston Hurlburt, P., and Janeway, C.A., Jr. 1997. A human homologue of the Drosophila toll protein signals activation of adaptive immunity. Nature. 388:394-397.

3. Modlin, R.L., Brightbill, H.D., and Godowski, P.J. 1999. The toll of innate immunity on microbial pathogens. N. Engl. J. Med. 340:1834-1835.

4. Ghosh, S., May, M.J., and Kopp, E.B. 1998. NF-кB and Rel proteins. Evolutionary conserved mediators of immune response. Annu. Rev. Immunol. 16:225-260.

5. Hoffmann, J.A., Kafatos, F.C., Janeway, C.A., and Ezekowitz, R.A. 1999. Phylogenetic perspectives in innate immunity. Science. 284:1313-1318.

6. Imler, J.L., and Hoffmann, J.A. 2000. Toll and Tolllike proteins: an ancient family of receptors signaling infection. Rev. Immunogenet. 2:294-304.

7. Kaiser, V., and Diamond, G. 2000. Expression of mammalian defensin genes. J. Leukoc. Biol. 68:779-784

8. Kaisho, T., and Akira. S. 2001. Toll-like receptors and their signaling mechanism in innate immunity. Acta Odontol. Scand. 59:124-130.

9. Silverman, N., and Maniatis, T. 2001. NF-кB signaling pathways in mammalian and insect innate immunity. Genes Dev. 15:2321-2342.

10. Baeuerle, P.A. 1998. Proinflammatory signaling: last pieces in the NF-KB puzzle? Curr. Biol. 8:R19-R22.

11. Baeuerle, P.A., and Baltimore, D. 1996. NF-кB: ten years after. Cell. 87:13-20.

12. Baeuerle, P.A., and Henkel, T. 1994. Function and activation of NF-кB in the immune system. Annu. Rev. Immun. 12:141-179.

13. Barnes, P.J., and Karin, M. 1997. Nuclear Factor- $\kappa B$ - A pivotal transcription factor in chronic inflammatory diseases. N. Engl. J. Med. 336:1066-1071.

14. Lawrence, T., Gilroy, D.W., Colville-Nash, P.R., and Willoughby, D.A. 2001. Possible new role for NF-кB in the resolution of inflammation. Nat. Med. 7:1291-1297

15. Verma, I., Stevenson, J.K., Schwarz, E.M., van Antwerp, D., and Miyamoto, S. 1995. Rel/NF-кB/ІкB family: intimate tales of association and dissociation. Genes Dev. 9:2723-2735.

16. Read, M.A., Whitley, M.Z., Williams, A.J., and Collins, T. 1994. NF-к B and I $\kappa$ B $\alpha$ : an inducible regulatory system in endothelial activation. J. Exp. Med. 179:503-512.

17. Beg, A.A., and Baldwin, A.S. 1993. The IкB proteins: multifunctional regulators of Rel/NF- $\mathrm{KB}$ transcription factors. Genes Dev. 7:2064-2070.

18. de-Martin, R., et al. 1993. Cytokine-inducible expression in endothelial cells of an I $\kappa \mathrm{B} \alpha$-like gene is regulated by NF-к B. EMBO J. 12:2773-2779.

19. Schmidt, A.M., Yan, S.D., Yan, S.F., and Stern, D.M 2000. The biology of the receptor for advanced glycation end products and its ligands. Biochim. Biophys. Acta. 1498:99-111.

20. Schmidt, A.M., Yan, S.D., Yan, S.F., and Stern, D.M. 2001. The multiligand receptor RAGE is a progression factor amplifying immune and inflammatory responses. J. Clin. Invest. 108:949-955.

21. Schmidt, A.M., et al. 1994. Cellular receptors for advanced glycation end products. Implications for induction of oxidant stress and cellular dysfunction in the pathogenesis of vascular lesions. Arterioscler. Thromb. 14:1521-1528.

22. Schmidt, A M., Yan, S.D., and Stern, D.M. 1995 The dark side of glucose. Nat. Med. 1:1002-1004

23. Schmidt, A.M., and Stern, D.M. 2001. Receptor for AGE (RAGE) is a gene within the major histocompatibility class III region: implications for host response mechanisms in homeostasis and chronic disease. Front. Biosci. 6:D1151-D1160.

24. Sugaya, K., et al. 1994. Three genes in the human MHC class III region near the junction with the class II: gene for receptor of advanced glycosylation end products, $\mathrm{PBX} 2$ homeobox gene and a notch homolog, human counterpart of mouse mammary tumor gene int-3. Genomics. 23:408-419.

25. Bierhaus, A., et al. 2001. Diabetes-associated sustained activation of the transcription factor nuclear factor-kB. Diabetes. 50:2792-2808.

26. Hofmann, M.A., et al. 2002. RAGE and arthritis: the G82S polymorphism amplifies the inflammatory response. Genes Immun. 3:123-135.

27. Basta, G., et al. 2002. Advanced glycation end products activate endothelium through signaltransduction receptor RAGE: a mechanism for amplification of inflammatory responses. Circulation. 105:816-822.

28. Schmidt, A.M., Hofmann, M., Taguchi, A., Yan, S.D., and Stern, D.M. 2000. RAGE: a multiligand receptor contributing to the cellular response in diabetic vasculopathy and inflammation. Semin. Thromb. Hemost. 26:485-493.

29. Ritthaler, U., et al. 1995. Expression of receptors for advanced glycation end products in peripheral occlusive vascular disease. Am. J. Pathol. 146:688-694.

30. Abel, M., et al. 1995. Expression of receptors for advanced glycosylated end products in renal disease. Nephrol. Dial. Transplant. 10:1662-1667.

31. Greten, J., et al. 1996. Expression of receptors for advanced glycation end products in uremia. Nephrol. Dial. Transplant. 11:786-790.

32. Tanji, N., et al. 2000. Expression of advanced glycation end products and their cellular receptor RAGE in diabetic nephropathy and nondiabetic renal disease. J. Am. Soc. Nephrol. 11:1656-1666

33. Hofmann, M.A., et al. 2001. Hyperhomocysteinemia enhances vascular inflammation and accelerates atherosclerosis in a murine model. J. Clin. Invest. 107:675-683.

34. Schmidt, A.M., and Stern, D.M. 2000. Atherosclerosis and diabetes: the RAGE connection. Curr. Atheroscler. Rep. 2:430-436.

35. Park, L., et al. 1998. Suppression of accelerated diabetic atherosclerosis by the soluble receptor for advanced glycation endproducts. Nat. Med. 4:1025-1031

36. Kislinger, T., et al. 2000. Receptor for advanced glycation end products mediates inflammation and enhanced expression of tissue factor in vasculature of diabetic apolipoprotein E-null mice. Arterioscler. Thromb. Vasc. Biol. 21:905-910.

37. Hofmann, M.A., et al. 1999. RAGE mediates a novel proinflammatory axis: the cell surface receptor for S100/calgranulin polypeptides. Cell. 97:889-901.

38. Taguchi, A., et al. 2000. Blockade of RAGE-amphoterin signaling suppresses tumour growth and metastases. Nature. 405:354-360.

39. Hou, F.F., et al. 2002. Receptor for advanced glycation end products on human synovial fibroblasts: role in the pathogenesis of dialysis-related amyloidosis. J. Am. Soc. Nephrol. 13:1296-3106.

40. Lalla, E., Lamster, I.B., Stern, D.M., and Schmidt, A.M. 2001. Receptor for advanced glycation end products, inflammation, and accelerated periodontal disease in diabetes: mechanisms and insights into therapeutic modalities. Ann. Periodontol. 6:113-118

41. Lue, L.F., et al. 2001. Involvement of microglial receptor for advanced glycation endproducts (RAGE) in Alzheimer's disease: identification of a cellular activation mechanism. Exp. Neurol. 171:29-45.

42. Goova, M.T., et al. 2001. Blockade of receptor for advanced glycation end-products restores effective wound healing in diabetic mice. Am. J. Pathol.
159:513-525.

43. Wautier, J.L., et al. 1996. Receptor-mediated endothelial cell dysfunction in diabetic vasculopathy. Soluble receptor for advanced glycation end products blocks hyperpermeability in diabetic rats. J. Clin. Invest. 97:238-243.

44. Anderson, K.V. 2000. Toll signaling pathways in the innate immune response. Curr. Opin. Immunol. 12:13-19.

45. Wang, H., et al. 1999. HMG-1 as a late mediator of endotoxin lethality in mice. Science. 285:248-251.

46. Schlaeger, T.M., et al. 1997. Uniform vascularendothelial-cell-specific gene expression in both embryonic and adult transgenic mice. Proc. Natl. Acad. Sci. U. S. A. 94:3058-3063.

47. Kasper, M. 2003. Pulmonary pathology of knockouts in mice lacking type I pneumocyte antigens. Ann. Anat. 185:144.

48. Yan, S.S., et al. 2003. Suppression of experimental autoimmune encephalomyelitis by selective blockade of encephalitogenic T-cell infiltration of the central nervous system. Nat. Med. 9:287-293.

49. Bouchon, A., Facchetti, F., Weigand, M.A., and Colonna, M. 2001. TREM-1 amplifies inflammation and is a crucial mediator of septic shock. Nature. 410:1103-1107.

50. Yan, S.D., et al. 2000. Receptor-dependent cell stress and amyloid accumulation in systemic amyloidosis. Nat. Med. 6:643-651.

51. Gold, J.A., et al. 2003. CD40 contributes to lethality in acute sepsis: in vivo role for CD40 in innate immunity. Infect. Immun. 71:3521-3528.

52. Ulloa, L., et al. 2002. Ethyl pyruvate prevents lethality in mice with established letal sepsis and systemic inflammation. Proc. Natl. Acad. Sci. U. S. A. 99:12351-12356.

53. Chavakis, T., et al. 2003. The pattern recognition receptor (RAGE) is a counter receptor for leukocyte integrins: a novel pathway for inflammatory cell recruitment. J. Exp. Med. 198:1507-1515.

54. Newcomb, D., Bolgos, G., Green, L., and Remick, D. G. 1998. Antibiotic treatment influences outcome in murine sepsis: mediators of increased morbidity. Shock. 10:110-117

55. Constien, R., et al. 2001. Characterization of a novel EGFP reporter mouse to monitor cre recombination as demonstrated by a Tie 2 cre mouse line. Genesis. 30:36-44.

56. Schwenk, F., Baron, U., and Rajewsky, K. 1995. A cretransgenic mouse strain for the ubiquitous deletion of loxP-flanked gene segments including deletion in germ cells. Nucleic Acids Res. 23:5080-5081.

57. Sambrook, J., Fritsch, E.F., and Maniatis, T. 1989. Molecular cloning: a laboratory manual. 2nd edition. Cold Spring Harbor Laboratory Press. Plainview, New York, USA

58. Mendel, I., Kerlero de Rosbo, N., and Ben-Nun, A. 1995. A myelin oligodendrocyte glycoprotein peptide induces typical chronic experimental autoimmune encephalomyelitis in $\mathrm{H}-2^{\mathrm{b}}$ mice: fine specificity and $T$ cell receptor $V \beta$ expression of encephalitogenic T cells. Eur. J. Immunol. 25:1951-1959.

59. Calandra, T., et al. 2000. Protection from septic shock by neutralization of macrophage migratory inhibitory factor. Nat. Med. 6:164-170.

60. Echtenacher, B., Falk, W., Männel, D.N, and Krammer, P.H. 1990. Requirement of endogenous tumor necrosis factor/cachectin for recovery from experimental peritonitis. J. Immunol. 145:3762-3766

61. Hofmann, M.A., et al. 1999. Peripheral blood mononuclear cells isolated from patients with diabetic nephropathy demonstrate increased activation of the oxidative-stress sensitive transcription factor NF-кB. Diabetologia. 42:222-232.

62. The R Development Core Team. 2003. The R reference manual: base package. Volumes 1 and 2. Network Theory Ltd. Bristol, United Kingdom. 